AJChE 2006, Vol. 6, No. 1, 36-43

\title{
Supercritical Water Oxidation for Toxic Organic Wastewater Disposal
}

\author{
Bambang Veriansyah \\ Benedictus Prabowo \\ Jae-Duck Kim \\ Supercritical Fluid Research Laboratory \\ Korea Institute of Science and Technology (KIST)-Department of Green Process and System Engineering \\ University of Science and Technology (UST) \\ 39-1 Hawolgok-dong, Seoungbuk-gu, Seoul, 136-791, KOREA \\ Email:vaveri@kist.re.kr
}

\begin{abstract}
The destruction of toxic organic wastewaters from munitions demilitarization and complex industrial chemicals clearly becomes an overwhelming problem if left to conventional treatment processes. Two options, incineration and supercritical water oxidation (SCWO), exist for the complete destruction of toxic organic wastewaters. Incinerator, on the one hand, has associated problems such as very high cost and public resentment; SCWO, on the other hand, has proven to be a very promising method for the treatment of various types of wastewaters with its extremely efficient organic waste destruction of $99.99 \%$ with none of the emissions associated with incineration. In this review, the concepts of SCWO, the results of and present perspectives on its applications, as well as the industrial status of SCWO are critically examined and discussed.
\end{abstract}

Keywords: Industrial status of SCWO, industrial wastewater, supercritical water oxidation (SCWO), and toxic wastewater treatment.

\section{INTRODUCTION}

The world is facing a waste crisis from organic and toxic wastes. Every year the amount of wastes generated by industrial and domestic sources increase rapidly. Moreover, the treatment of organic and toxic waste is becoming more difficult and costly because of more stringent treatment standards and discharge limitations.

Public health concerns are the driving force for the continued legislation aimed at providing a cleaner and safer environment. Furthermore, Environmental Protection Agency (EPA) goals suggest destruction levels of up to $99.9999 \%$ for some compounds and the use of totally enclosed treatment facilities. Increased environmental concerns and unfavorable public opinion have challenged the continuing application of conventional waste management techniques $(\mathrm{Li}$ et al. 1991).

The conventional methods currently being used to treat the different types of organic and toxic wastes include adsorption, biological oxidation, chemical oxidation, land-based, and incineration technologies. Each treatment method has its shortcomings and, therefore, may not be the best option for treating organic and toxic wastes. Therefore, additional treatment of the adsorbent is required to destroy the contamirant and to regenerate the adsorbent.

Supercritical water oxidation (SCWO) has been proposed as a technology capable of destroying a wide range of hazardous organic waste. It has drawn much attention because it 
effectively destroys a large variety of high-risk wastes resulting from munitions demilitarization and complex industrial chemicals.

The primary advantage of the SCWO process over such land-based alternatives as land filling, deep-well injection, and lagooning is the destruction method. Land-based disposal does not address the ultimate destruction of toxic waste components and can result in the contamination of the surrounding soil and groundwater. Deepwell injection systems are subject to plugging or fouling if an organic concentration of $1 \%$ or higher is allowed. Landfills and lagoons can contribute to the contamination of the air by volatile organics. Increased public concern and regulatory action will restrict or prohibit the land-based disposal of many organic wastes in the future.

Destruction methods based on oxidation of organic content for aqueous wastes include activated carbon treatment, biological treatment, incineration, wet air oxidation and supercritical oxidation. For very dilute aqueous waste whose organic contents are less than $1 \%$, activated carbon treatment or biological treatment is often an effective destruction method. In activated carbon treatment, organics are first adsorbed onto carbon and then oxidized during regeneration of carbon. Partially oxidized materials are perfectly destroyed by after-burner treatment. Main cost is proportional to the organic content. So this method is not economically useful for waste containing more than $1 \%$ organic. Biological treatment systems often become poisoned and cannot be sustained for many wastes with organic concentrations of $1 \%$ or more.

Incineration, on the other hand, is restricted for economic reasons to waste streams relatively high organic concentrations. To attain high destruction efficiency for hazardous and toxic wastes, incineration must be operated at very high temperatures at $900 \sim 1100 \div$ and often with excess air of $100 \sim 200 \%$. With aqueous wastes, the energy required to bring the water component of the waste to this temperature is substantial. For the aqueous wastes with organic content more than $25 \%$, the heat required for high temperature can be generated from wastes. With decreasing organic content, the supplemental fuel required to satisfy the energy balance becomes a major cost. Thus, controlled incineration of aqueous waste with less than $20 \%$ organics is only consideration in extenuating circumstances (Thomason and Modell 1984). Incineration is also being regulated to restrict stack gas emissions to the atmosphere. Extensive equipment must now be used downstream of the reaction system to remove $\mathrm{NO}_{\mathrm{x}}$, acid gasses, acid gases, and particulates from the stack gases before discharge. The cost of this equipment often exceeds that of the incinerator itself.

In the range of concentration of 1 to $20 \%$ organic, wet air oxidation or supercritical water oxidation is far less costly than incineration or active carbon treatment. Wet air oxidation (WAO) has been offered as a method to treat wastewater, industrial wastes and sludge. From a public perception standpoint, WAO is more favorable than incineration, land application, deep well injection and ocean dumpiriy because the waste products can be completely converted to inert materials and the process can be conducted as a closed system which does not produce any hazardous byproducts. Capital costs are often higher than incineration; however, operating costs are lower. It is possible to recover energy and inorganic in WAO. Wet air oxidation, commonly associated with sludge conditioning and some organic destruction is a low-temperature process (Boock 1996).

The Zimpro-Passavant's wet air oxidation process is typically operated in a temperature range of $150 \div$ to $350 \div$ and pressure range of 2 to $20 \mathrm{MPa}$. The operating pressure is maintained well above the saturation pressure corresponding to the operating temperature so that the reaction is carried out in the liquid phase. Residence times may range from $15 \mathrm{~min}$ to $120 \mathrm{~min}$, and the chemical oxygen demand (COD) removal may typically be about $75 \%$ to $90 \%$. Volatile acids constitute a substantial portion of remaining COD. The formation of volatile acids, particularly acetic acid, is a limitation for WAO. Furthermore, the effluent from incomplete (partial) wet oxidation of some wastewaters may be intensely colored and toxic (Li et al. 1991).

The above examples illustrate the utility of WAO as an alternative to incineration for the treatment of dilute aqueous wastes. However, a number of compounds, including m-xylene and acetic acid are refractory towards oxidation at these conditions. Additionally, WAO often cannot achieve the $99.9+\%$ destruction efficiencies that 


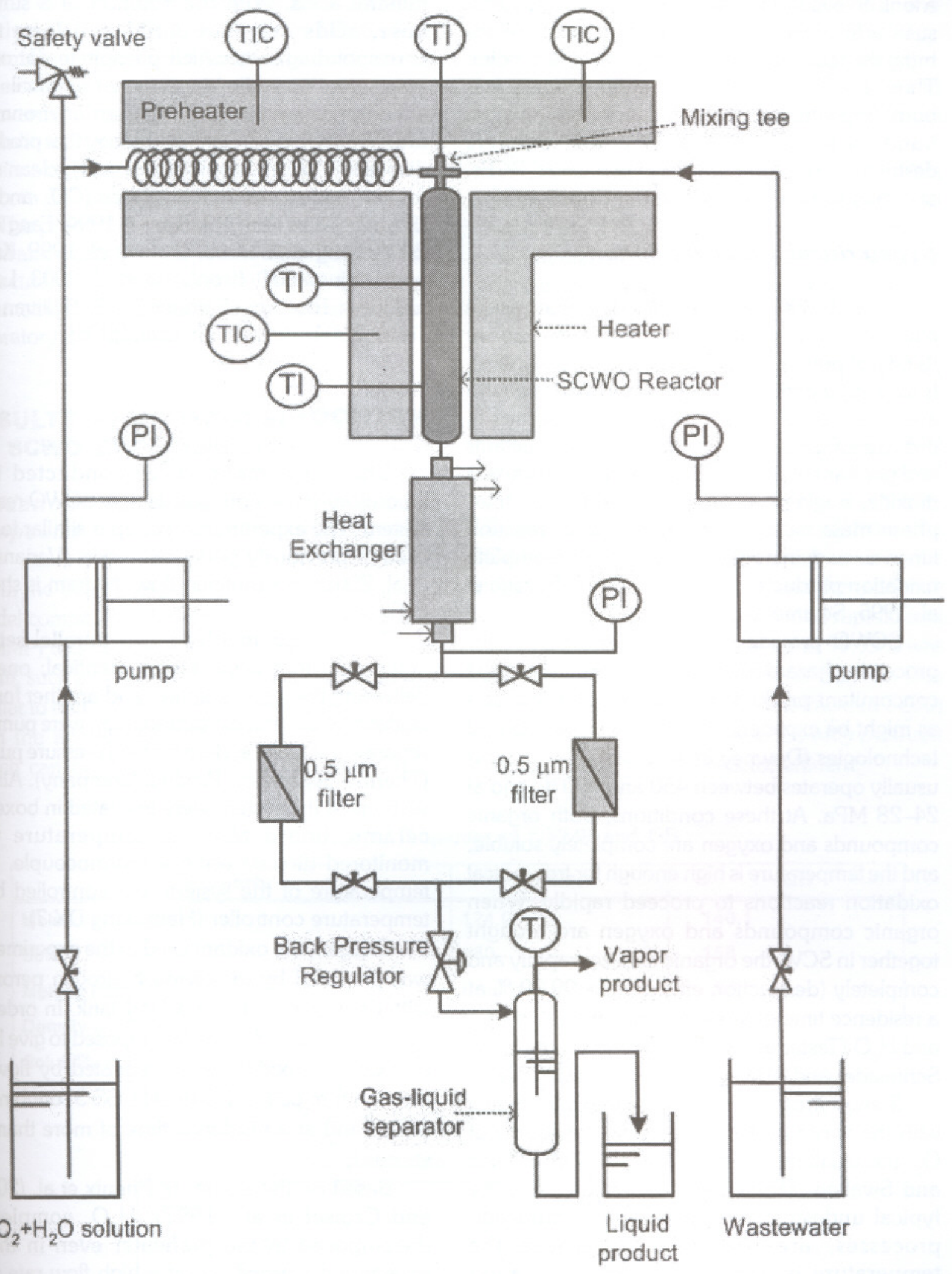

Figure 1. Simplified Flow Diagram of SCWO System 
many newer regulations require. This motivated a look at oxidation under more severe conditions, such as higher temperatures and pressures, which bring the reaction mixture above its critical point. Thus, the supercritical oxidation process was born. Supercritical water oxidation, on the other hand, is known to attain nearly complete destruction of various organics, such as PCBs, and dioxins in a very short time (Boock 1996).

\section{Supercritical water oxidation}

Supercritical water oxidation is defined as the oxidation process which occurs in water above its critical point $\left(T_{c}=374^{\circ} \mathrm{C}\right.$ and $\left.P_{c}=22.1 \mathrm{MPa}\right)$. It uses supercritical water as a reaction medium and exploits its unique solvating properties to provide enhanced solubility to organic reactants and permanent gases such as oxygen and carbon dioxide, single-phase environment free of interphase mass transfer limitations, faster reaction kinetics, and increased selectivity to complete oxidation products (Tester et al. 1993, Savage et al. 1995, Schimeider and Abeln 1999).

SCWO provides a potential alternative for processing hazardous military wastes without the concomitant production of noxious by-products as might be experienced with combustion-based technologies (Downey et al. 1995). The process usually operates between 450 and $600{ }^{\circ} \mathrm{C}$ and at 24-28 MPa. At these conditions, both organic compounds and oxygen are completely soluble, and the temperature is high enough for free radical oxidation reactions to proceed rapidly. When organic compounds and oxygen are brought together in SCW, the organic oxidizes rapidly and completely (destruction efficiency $>99.99 \%$ at a residence time of less than one minute) to $\mathrm{CO}_{2}$ and $\mathrm{H}_{2} \mathrm{O}$ (Tester et al. 1993, Savage et al. 1995, Schmieder and Abeln 1999, Modell et al. 1989).

If any nitrogen is present, either introduced with the waste or if air is used as the source of $\mathrm{O}_{2}$, the resulting product is $\mathrm{N}_{2}$ or $\mathrm{N}_{2} \mathrm{O}$ (Killilea and Swallow 1992). $\mathrm{NO}_{\mathrm{x}}$ and $\mathrm{SO}_{\mathrm{x}}$ gases, the typical undesired by-products of combustion processes, are not formed because the temperature is too low for these oxidation pathways to be favored.

Any $\mathrm{N}_{2} \mathrm{O}$ found can be catalytically converted to $\mathrm{N}_{2}$. Heteroatoms (e.g., chlorine, phosphorous, and sulfur) react to form their corresponding mineral acids. With the addition of a suitable base, acids are neutralized and form their corresponding salts which precipitate out of the reacting mixture allowing for their removal. It [?] already proved that SCWO is an environmentfriendly waste treatment technology that produces disposable clean liquid (pure water), clean solid (metal oxides), and clean gases $\left(\mathrm{CO}_{2}\right.$ and $\left.\mathrm{N}_{2}\right)$ [Bianchetta et al. 1999, Burner 1994, Fang et al. 2000, Fang et al. 2005, Goto et al. 1999, Kritzer and Dinjus 2001, Kronholm et al. 2003, Lee et al. 2004, Rice and Steeper 1998, Sullivan and Tester 2004, Veriansyah et al. 2005].

\section{METHOD}

The experiments were conducted in a laboratory-scale, continuous-flow SCWO reactor system. The experimental set-up is similar to that used in previously published works (Veriansyah et al. 2005). A simplified flow diagram is shown in Figure 1.

The system involved two parallel sets of equipment that were almost identical: one for delivering the waste solution and another for the oxidant. Waste and oxidant solution were pumped separately into the system by high pressure pumps (Thermo Separation Product Company). All hot sections of the system were insulated in boxes of ceramic board and the temperature was monitored directly using a thermocouple. The temperature of the system was controlled by a temperature controller (Hanyoung DX 7).

Oxygen, the oxidant used in the experiments, was prepared by dissolving hydrogen peroxide with deionized water in a feed tank. In order to assure that all of $\mathrm{H}_{2} \mathrm{O}_{2}$ is decomposed to give $\mathrm{H}_{2} \mathrm{O}$ and $\mathrm{O}_{2}$, the oxidant was preheated by flowing through $6 \mathrm{~m}$ coiled 1/8-in O.D. SS 316 tubing at $600^{\circ} \mathrm{C}$ and at a residence time of more than 14 seconds.

Based on the studies of Phenix et al. (2002) and Croiset et al. (1997), $\mathrm{H}_{2} \mathrm{O}_{2}$ completely decomposed in the preheater even in those experiments carried out at a high flow rate and at low temperature. Waste solution was preheated by flowing through $0.5 \mathrm{~m} 1 / 8$-in O.D. SS 316 tubing. The solutions mixed at the reactor 
entrance in a SS 316 cross and then entered the reactor, which was constructed from a $300 \mathrm{~mm}$ length of 12.7-mm O.D. and 9.4-mm I.D. SS 316 tubing. Upon leaving the reactor, the effluent was cooled rapidly in a shell and tube heat exchanger; afterwards, the particles were filtered out by a 0.5$\mu \mathrm{m}$ inline filter before being depressurized to ambient condition by a back-pressure regulator (Tescom Co. 26-1721-24).

The product stream was then separated into liquid and vapor phases. The liquid products were collected in a graduated cylinder, and their volumetric flow rates were measured at ambient laboratory conditions.

\section{RESULTS AND DISCUSSIONS OF SCWO EXPERIMENTS}

\section{Oxidation of toxic organic model compound}

In the SCWO experiment with toxic organic model compound, dimethyl methylphosphonate (DMMP) was chosen as a simulant for the never agent, such as VX and GB, since it is structurally similar to and has physical properties comparable with the actual agent. The chemical structure which can be described DMMP, VX and GB is shown in Figure 2 where $R_{1}$ and $R_{2}$ are differing functional groups. For DMMP, $R_{1}=\mathrm{OCH}_{3}$ and $R_{2}=\mathrm{CH}_{3}$; for $\mathrm{GB}, R_{1}=\mathrm{F}$ and $R_{2}=\mathrm{CH}\left(\mathrm{CH}_{3}\right)_{2}$; and for $\mathrm{VX}, R_{1}=\mathrm{SCH}_{2} \mathrm{CH}_{2} \mathrm{~N}\left(\mathrm{C}_{3} \mathrm{H}_{7}\right)_{2}$, and $R_{2}=$ $\mathrm{CH}_{2} \mathrm{CH}_{3}$. Select physical properties of DMMP and Agent GB are listed in Table 1 (Akzo Nobel Function Chemical 2002).

The experiments were performed at $24 \mathrm{MPa}$ with $\mathrm{H}_{2} \mathrm{O}_{2}$ as oxidant. The reaction temperatures ranged from 398 to $633^{\circ} \mathrm{C}$. Table 2 provides the experimental ranges and variables. The oxidation reaction in this study can be represented by following stoichiometric Eq. (1).

$$
\mathrm{C}_{3} \mathrm{H}_{9} \mathrm{O}_{3} \mathrm{P}+10 \mathrm{H}_{2} \mathrm{O}_{2} \rightarrow 3 \mathrm{CO}_{2}+\mathrm{H}_{3} \mathrm{PO}_{4}+13 \mathrm{H}_{2} \mathrm{O}
$$

The conversion was monitored by analyzing the total organic carbon (TOC) in the liquid effluent samples using TOC Analyzer (Shimadzu TOC-VCPN). The results obtained from the SCWO of DMMP gave a TOC conversion value of $58.0-99.99 \%$. It was found that the oxidative decomposition of DMMP proceeded rapidly and that a high TOC conversion of up to $99.99 \%$ was obtained within 11 seconds at $555^{\circ} \mathrm{C}$. Gas analyses using GC-TCD (Hewlett-Packard 5890) showed that $\mathrm{O}_{2}$ and $\mathrm{CO}_{2}$ were the only products detected in the gaseous reactor effluent.

Table 1. Physical Properties of DMMP and GB

\begin{tabular}{|l|l|l|}
\hline \multicolumn{1}{|c|}{ Property } & \multicolumn{1}{c|}{ DMMP } & \multicolumn{1}{c|}{ GB } \\
\hline \hline Molecular Weight & 124.08 & 140.1 \\
Boiling Point, ${ }^{\circ} \mathrm{C}$ & 180 & 158 \\
Melting Point, ${ }^{\circ} \mathrm{C}$ & Pour point: $<-50$ & -56 \\
Density at $25^{\circ} \mathrm{C}, \mathrm{g} / \mathrm{mI}$ & 1.17 & 1.09 \\
Solubility in Distilled Water $(\mathrm{g} / 100 \mathrm{~g})$ at $25^{\circ} \mathrm{C}$ & miscible & miscible \\
\hline
\end{tabular}

Table 2. Experimental Variables and Ranges

\begin{tabular}{|l|l|}
\hline \multicolumn{1}{|c|}{ Experimental Variable } & \multicolumn{1}{c|}{ Range } \\
\hline \hline Pressure, $P$ & $24 \mathrm{MPa}$ \\
Temperature, $T$ & $398-633^{\circ} \mathrm{C}$ \\
Residence Time, $t$ & $4-15 \mathrm{~s}$ \\
TOC Concentration at Reactor Inlet & $2-32 \mathrm{mmo} / \mathrm{l}$ \\
$\mathrm{H}_{2} \mathrm{O}_{2}$ Concentration at Reactor Inlet & $38-300 \mathrm{mmol} / \mathrm{l}$ \\
\hline
\end{tabular}


Table 3. Property of LCD Wastewater in Its Concentrated Form

\begin{tabular}{|c|c|}
\hline Description & Value $(\mathbf{m g} / \mathbf{l})$ \\
\hline \hline COD & $37,191-41,323$ \\
BOD & $26,250-81,287$ \\
Total Cr & $3,495-3,622$ \\
Total N & $10,987-54,306$ \\
\hline
\end{tabular}

\section{Oxidation of real wastewater}

Wastewater from an LCD manufacturing plant was treated with SCWO. The original wastewater contained a wide variety of organic pollutants and heavy metal chromium, as shown in Table 3. Experiments were carried out between 400 and $605{ }^{\circ} \mathrm{C}$ at a pressure of 25 $\mathrm{MPa}$, a residence time of $15 \mathrm{~s}$, and an oxidant excess of $132 \%$.

The oxidative decomposition of wastewater was evaluated by chemical oxygen demand (COD) analysis according to Standard Method 5220D. The results of the experiments are shown in the Figures 3 and 4 . These figures show that the conversion of $\mathrm{COD}$ increases and that the color changes gradually with the reaction temperature. Likewise, a COD conversion of up to $99.99 \%$ and a clear effluent were obtained at a reaction temperature $605^{\circ} \mathrm{C}$. This was an

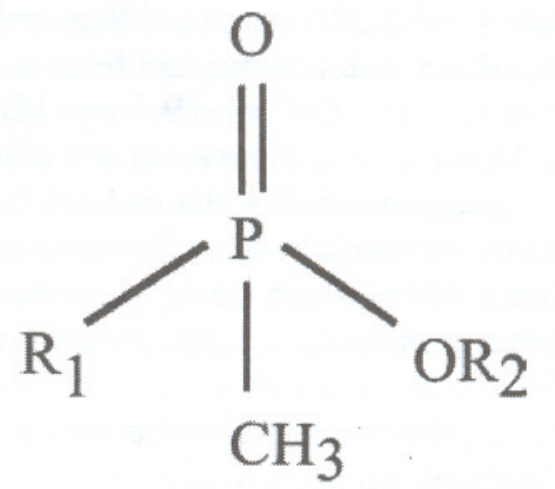

Figure 2. Structure of Chemical Agent Welfare

indication that most organic compounds disappear as reaction temperature increasd.

Gas analyses using GC-TCD showed that $\mathrm{O}_{2}$, $\mathrm{N}_{2}$, and $\mathrm{CO}_{2}$ were the only reaction products detected in the gaseous reactor effluent. There was no evidence of hydrogen, carbon monoxide, and methane being formed. In addition to the destruction of organic matter, in situ formation of chromium oxide nanoparticles by decomposition of heavy metal chromium contained in the wastewater was found during the SCWO process.

\section{CONCLUSIONS}

The studies performed on state-of-the-art laboratory scale showed that SCWO technology is a very promising method for the treatment of toxic organic wastewaters. Furthermore, for

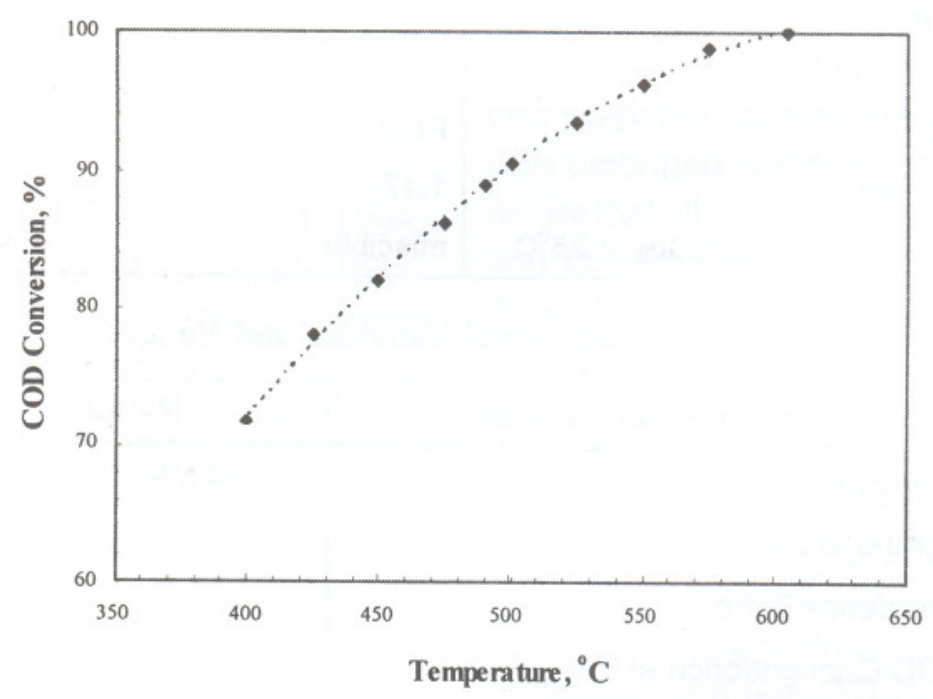

Figure 3. Experimental Results of SCWO on Real Wastewater 


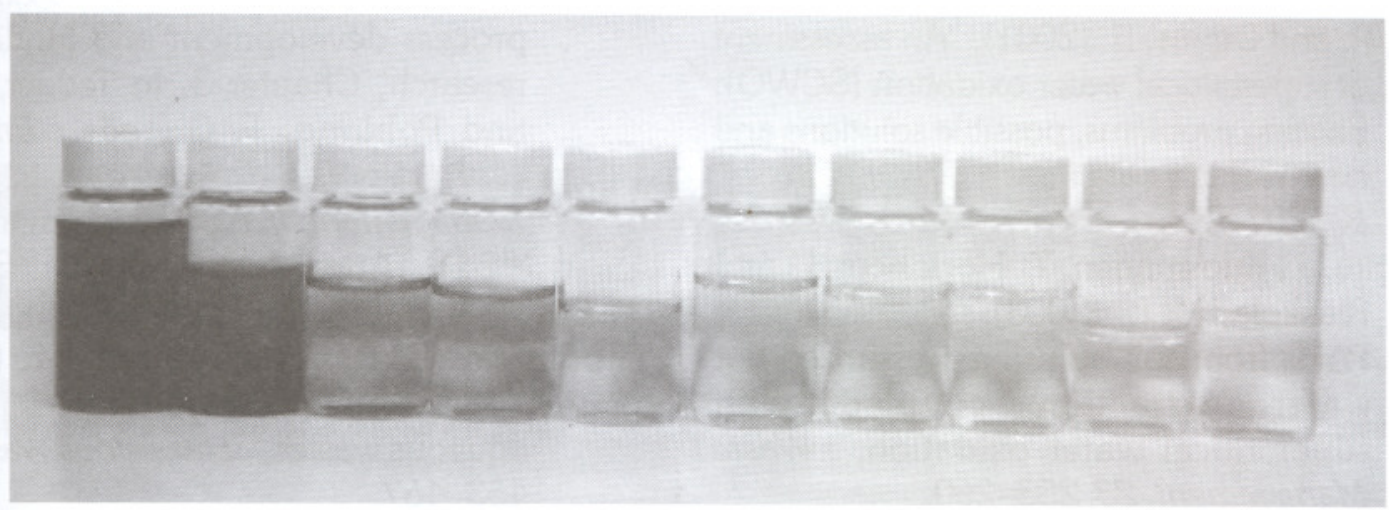

Figure 4. Samples of Real Wastewater Before and After SCWO Treatment

wastes like $\mathrm{LCD}$ wastewater that contain valuable heavy metals, SCWO treatment offers, besides an extremely clean effluent, the possibility of recovering these important compounds. The extremely clean inorganic material recovered through SCWO ought to increase interest in this treatment method. This type of waste may very well be the breakthrough of SCWO.

\section{ACKNOWLEDGMENTS}

This work has been supported by the National Research Laboratory Program for Supercritical Fluid and the authors would like to thank the Ministry of Science and Technology, Korea.

\section{REFERENCES}

Akzo Nobel Function Chemical. (2002). "MSDS of Fyrol DMMP," Safety Data Sheet, http:/ /www.phosphoruschemicals.com/pdf/ fyrol\%20dmmp\%20msds.pdf

Bianchetta, S., Li, L., and Gloyna, E. F. (1999). "Supercritical water oxidation of methylphosphonic acid," Ind. Eng. Chem. Res., 38, 2902-2910.

Boock, L.T. (1996). A quantitative analysis of reactions in supercritical water: Experimental kinetics and mechanistic modeling, Ph.D. Dissertation, The University of Delaware.

Brunner, G. D. (1994). "Extraction and destruction of waste with supercritical water," In Kiran, E., and Sengers, J. M. H. L., eds., Supercritical fluids, Kluwer
Academic Publisher, the Netherlands. 697-705.

Croiset, E., Rice, S. F., and Hanush, R.G. (1997). "Hydrogen peroxide decomposition in supercritical water," AIChE J. 43, 9, 2343-2352.

Downey, K. W., Snow, R. H., Hazlebeck, D. A., and Roberts, A. J. (1995). "Corrosion and chemical agent destruction: Research on supercritical water oxidation of hazardous military wastes," Chapter 21, In Hutchenson, K. W., and Foster, N. R., eds., Innovation in supercritical fluids science and technology, ACS Symposium Series \#608, American Chemical Society, Washington, D. C.

Fang, Z., Xu, S. K., and Kozinski, J. A. (2000). "Behavior of metals during combustion of industrial organic wastes in supercritical water," Ind. Eng. Chem. Res., 39, 4536-4542.

Fang, Z., Xu, S. K., Smith, Jr., R. L., Arai, K., and Kozinski, J. A. (2005). "Destruction of deca-chlorobiphenyl in supercritical water under oxidizing conditions with and without $\mathrm{Na}_{2} \mathrm{CO}_{3}, " J$. Supercrit. Fluids, 33, 247-258.

Goto, M., Nada, T., Kodama, A., and Hirose, T. (1999). "Kinetic analysis for destruction of municipal sewage sludge and alcohol distillery wastewater by supercritical water oxidation," Ind. Eng. Chem. Res., 38, 1863-1865.

Killilea, W. R., and Swallow, K. C. (1992). "The fate of nitrogen in supercriticalwater oxidation," J. Supercrit. Fluids., 5, 72-78. 
Kritzer, P., and Dinjus, E. (2001). "An assessment of supercritical water oxidation (SCWO): Existing problems, possible solutions and new reactor concepts," Chem. Eng. J., 83, 207-214.

Kronholm, J., Kuosmanen, T., Hortonen, K., and Riekkola, M.-L. (2003). "Destruction of $\mathrm{PAHs}$ from soil by using pressurized hot water extraction coupled with supercritical water oxidation," Waste Management, 23, 253-260.

Lee, H.-C., In, J.-H., Hwang, K.-Y., and Lee, C.H. (2004). "Decomposition of ethylenediaminetetraacetic acid by supercritical water oxidation," Ind. Eng. Chem. Res., 43, 3223-3227.

Li, L., Chen, P., and Gloyna, E. F. (1991). Generalized kinetic model for wet oxidation of organic compounds, AIChE J., 37, 11, 1687-1697.

Modell, M. (1989). "Supercitical water oxidation," In Freeman, H. M., ed., Standard handbook of hazardous waste treatment and disposal, McGraw-Hill, New York.

Phenix, B. D., DiNaro, J. L., Tester, J. W., Howard, J. B., and Smith, K. A. (2002). "The effect of mixing and oxidant choice on laboratory-scale measurements of supercritical water oxidation kinetics," Ind. Eng. Chem. Res., 41, 624-631.

Rice, S. F., and Steeper, R. R. (1998). "Oxidation rates of common organic compounds in supercritical water," J. Hazard. Mater., 59, 261-278.

Savage, P. E., Gopalan, S., Mizan, T. I., Martino, C. J., and Brock, E. E. (1995). "Reactions at supercritical conditions: Application and fundamentals," $A I C h E$ J., 41, 7, 1723-1778.

Schmieder, H., and Abeln, J. (1999). "Supercritical water oxidation: State of the art," Chem. Eng. Technol., 22, 11, 903-908.

Sullivan, P. A., and Tester, J. W. (2004). "Methylphosphonic acid oxidation kinetics in supercritical water," AIChE J., 50, 3, 673-683.

Tester, J. W., Holgate, H. R., Armellini, F. J., Webley, P. A., Killilea, W. R., Hong, G. T., and Barner, H. T. (1993). Supercritical water oxidation technology: A review of process development and fundamental research, Chapter 3, In Tedder, D. W., and Pohland, F. G., eds., Emerging technologies in hazardous waste management III, ACS Symposium Series \#518, American Chemical Society, Washington, D. C.

Thomason, T. B., and Modell, M. (1984). "Supercritical water destruction of aqueous wastes," Hazardous Waste, 1, 4, 453-467.

Veriansyah, B., Kim, J.-D., Lee, J.-C., and Lee, Y.-W. (2005). "OPA oxidation rates in supercritical water," J. Hazard. Mater. B124, 119-124. 